\title{
Influence of Molybdenum as Alloying Element on Corrosion Resistance of Stainless Steel Rebar in Simulated Concrete Pore Solution with different $\mathrm{pH}$
}

\author{
Jitao Fan ${ }^{1, *}$ Qizhi Zhang ${ }^{2}$ \\ ${ }^{1}$ Zhumadian Construction Company, Zhumadian, 463000, China \\ ${ }^{2}$ Huanghuai University, Zhumadian, 463000, China \\ *E-mail: fanjitao111@163.com, 20070359@ @uanghuai.edu.cn,
}

doi: $10.20964 / 2020.08 .10$

Received: 6 October 2019 / Accepted: 24 November 2019 / Published: 10 July 2020

Reinforcement stainless steel working electrode was successfully used in electrochemical testing after $5 \mathrm{~h}$ immersion in simulated concrete pore (SCP) solutions. The influence of molybdenum (Mo) element addition into the alloy steel on the corrosion behavior of steel rebar in different $\mathrm{pH}$ value of SCP solutions was evaluated using Mott-Schottky and electrochemical impedance spectroscopy (EIS) analysis. Results showed that $\mathrm{pH}$ value of SCP solution had a significant effect on the formation of the passive layer on reinforcement steel. The EIS results indicated that the increase of Mo content improves the passive layer stability, boosts the polarization resistance and enhances the corrosion resistance of the steel rebar. Furthermore, the value of the double-layer capacitance decreased as $\mathrm{pH}$ and Mo content reduced, which revealed that the passive film thickness increased and the resulting protective capacity enhanced when the $\mathrm{pH}$ and Mo content of reinforced concrete was gradually increased. The minimum values of donor density were obtained for a Mo concentration of $3 \mathrm{wt} \%$ and $12 \mathrm{pH}$ value of solution which are in good agreement with the experimental results.

Keywords: Stainless steel rebar; $\mathrm{pH}$ effect; Molybdenum content; Corrosion corrosion; Electrochemical impedance spectroscopy; Simulated concrete pore solution

\section{$\underline{\text { FULL TEXT }}$}

(C) 2020 The Authors. Published by ESG (www.electrochemsci.org). This article is an open access article distributed under the terms and conditions of the Creative Commons Attribution license (http://creativecommons.org/licenses/by/4.0/). 